Commissioners in Lunacy for the years 1902 and 1903 it occurred nine times in 18,601 deaths and of these four cas es were those of males and five were those of females, showing that sex has little to do with its incidence.

In the present case the patient was a man, aged 76 years, who died in the Bucks County Asylum after 14 month' residence. Mentally he was somewhat depressed and suicidal on admission, his condition passing into one of mild dementia. Physically he was rather feeble but stout and flabby. The pulse was regular but weak, the heart sounds were feeble and distant in character, and cardiac dulness was considerably increased. There was nothing of importance in the subsequent bistory of the case and the patient appeared as usual on the night of his death. He was found dead on the floor of his room, having apparently got out of bed and collapsed.

At the post-mortem examination the pericardium was found to be much distended with blood-clot and fluid. In the heart a small tear was found in the left ventricle, anteriorly, at the lower end near the apex in the long axis of the organ and plugged with blood clot. Internally the tear was found to be somewhat smaller than externally. The heart was much hypertrophied (weight $18 \frac{3}{4}$ ounces), more especially the left ventricle, the muscle was soft, fatty, and very friable, while the valves and coronary arteries were atheromatous. The immediate cause of the rupture could not be determined, the factor of extra strain or stress being practically eliminated.

Stone, Bucks.

\section{A CASE OF VARIOLA FOLLOWING AN} UNUSUAL COURSE.

By Richard Rolfe, M.B. Cantab.,

MEDICAL OFFICER OF AVONMOUTH HOSPITAI, BRISTOL.

THE following case presents some very unusual features and, perhaps, similar cases may in part account for the difficulty which is too often experienced in checking an epidemic of small-pox. The patient, a man, aged 30 years, had been vaccinated in infancy and showed four well-marked scars on his left arm. He had by an oversight not been revaccinated, though revaccination had been offered to him and he had been warned of the necessity for it. On Oct. 31st and Nov. 1st he was exposed to infection by entering huts from which small-pox patients were being removed and by helping in their removal. On the evening of Nov. 11th he began to feel out of sorts and on the morning of the 12th he came to me for treatment, complaining of headache and pains in the back and limbs. His temperature was normal. He was sent home to bed and given a saline mixture every four hours. On the 13th he was very -ill. The pains in his back and limbs had increased so that he could get no rest; his head also ached. His tongue was thickly furred, he was parched with thirst, and there was complete anorexia. His pulse was full and bounding and his temperature, taken in the axilla, was $103.8^{\circ} \mathrm{F}$. $\mathrm{He}$ presented all the features of moderately severe initial fever of variola and was removed to a temporary isolation hospital. During the night his temperature fell to normal and he felt quite comfortable when seen in the morning. A careful examination showed no rash on any part of his body. As the onset of his illness had been so typical and the date of his sickening corre sponded so exactly with the usual incubation period of small-pox Dr. D. S. Davies, medical officer of health of Bristol, who kindly saw him for me, regarded the case as one of variola sine eruptione and the patient was therefore kept isolated. On the 16 th he was revaccinated in three places on his left arm, lymph obtained from Messrs. Ferris and Co. being used. This was done for diagnostic reasons. His temperature remained normal and he felt quite well. On the 18th a few papules appeared about his arms and legs, on his scalp, and the back of his neck. These became resicular the same day but there was no rise of temperature. At the same time the patient complained of some irritation at the site of his vaccination and all three places swelled a little and looked as if about to take. This swelling, however, passed off in a very few hours. On the 19th there were some 18 or 19 spots on the patient. They were vesicular and were surrounded by a zone of induration. Dr. Davies again saw the case and pronounced it to be undoubtedly one of modified variola. During the next few days several of the spots dried up and disappeared but others, especially two on the left hand, one on the left leg, and one under the sole of the right foot, ran a typical course, becoming pustular and only disappearing after a full fortnight. During this time the vaccination marks several times swelled up slightly and caused some irritation. Nothing very definite happened, however, till Dec. 2nd, 16 days after vaccination, on which day one of the marks assumed the form of a definite vaccine vesicle of quite average size. This occurred just at the time that the variola spots were drying up and seems to indicate that the toxin of variola had held the vaccine, which had been introduced too late to prevent an attack of small-pox, in an inert condition without destroying it until the variola had exhausted itself.

I have to thank Dr. Davies for seeing the case for me and for allowing his name to appear in this account, thereby dispelling any doubt which might arise as to the nature of the rash. Such a case as this might very easily be looked upon as one of influenza; and even if the patient were known to have been in contact with small-pox when no rash was discoverable on the third or fourth day and he appeared well and had a normal temperature, a busy practitioner could hardly be expected to follow the case up and would probably dismiss it as cured with possibly disastrous results to unprotected persons who came in contact with it.

During the summer there have been two or three slight outbreaks of small-pox in this locality. Most of the cases have been of an exceedingly mild type with initial symptoms not more marked than in the case described and in many of them the number of spots was very limited. Such unusually modified cases appear to approach the "vanishing point" of variola when the disease no longer becomes recognisable.

Avonmouth.

\section{d attirtor}

\section{HOSPITAL PRACTICE, BRITISH AND FOREIGN.}

Nulla autem est alia pro certo noscendi via, nisi quamplurimas ot morborum et dissectionum historias, tum aliorum tum proprias morborum et dissectionum historias, tum aliorum tum proprias Morb., lib. iv., Procmium.

\section{LEEDS GENERAL INFIRMARY.}

\section{A CASE OF ACUTE INVERSION OF THE UTERUS.}

(Under the care of Dr. J. B. HELLIER.)

THE patient was a woman, aged 20 years, and was taken into the Leeds General Infirmary from a village about six miles distant on the evening of Nov. 28th, 1904, with inverted uterus. She had been married two and a quarter years. Her first confinement had been difficult; she was in labour three days and had flooding afterwards. On the morning of the day of admission her second labour began at 3 A.M. and she was delivered of a living child at 8.30 A.M. a midwife being in attendance. A medical man was called in after labour and he found the uterus inverted and prolapsed lying on the bed with the placenta attached to it, but there did not seem to have been much loss of blood. He peeled the placenta off and, as he thought, reduoed the inversion. Subsequently the patient had much vomiting and the uterus again appeared outside. She was then taken in a cab to the infirmary. On admission she was found to be a poorly nourished but not otherwise unhealthy young woman. She was pale but not blanched; the pulse was 150 and the urine was normal. Dr. Hellier saw her at 10.30 P. M. Chloroform was administered and she was then placed in the lithotomy position and the parts were thoroughly disinfected. The inverted fundus was grasped with the right hand, pressure being made with the finger tips on the periphery of the tumour; at the same time counter-pressure was made with the left hand above the pubes. A few minutes of such bimanual taxis sufficed to reduce the inversion. The surface where the placenta had been attached was rather ragged in appearance but there were no fragments of placenta left adherent. The patient improved rapidly after the operation. On the fourth day the tem. perature rose to $101^{\circ} \mathrm{F}$. and the discharge was a little 